\title{
Countermeasures of Tourism Development in Southern Xinjiang under the Perspective of Cultural and Creative Tourism
}

\author{
$\mathrm{Li} \mathrm{Li}^{1}$, Chuanhui Zhang ${ }^{2 *}$ \\ ${ }^{1,2^{\star}}$ College of Economics and Management, Tarim University, Alar, Xinjiang, 843300 \\ ${ }^{\mathrm{a}}$ email, ${ }^{\mathrm{b}}$ email
}

Keywords: Cultural and Creative Tourism; Southern Xinjiang; Tourism Development

\begin{abstract}
In recent years, with the continuous improvement of people's living standards, China's tourism industry has been the strong development in the tourism industry, the market is increasing competitive pressure, in order to stand out in the fierce competition in the market, should travel from the cultural and creative perspective down the development of the tourism industry, innovative concept of tourism in order to develop tourism in the new world. Therefore, the Southern Xinjiang tourism industry should seek to develop creative tourism from Cultural Perspective.
\end{abstract}

\section{Introduction}

Under the background of China's economy growing, people on China's cultural development is given higher priority in the cultural industry, cultural and creative is an important genus in the development of a pluralistic society, the creative industry has a very large potential in the development process in all walks of life, the culture and creative industries can become a new growth point of economic development. With the reform of cultural system, our country has been promoting the integration of cultural industries and tourism industry, but also continuing to extend the cultural industry chain, thereby increasing the added value of the industry.

\section{Understand Southern Xinjiang Tourism Resources from View of Cultural and Creative Tourism}

Xinjiang is a region rich in tourist resources, a wide variety of tourism resources, type is also very complete, but also with a variety of versatile material, it has good prospects for development. The southern border region is an important part of the Xinjiang region, including in Hotan, Aksu Prefecture, Bayinguoleng Mongol Autonomous Prefecture, Kashi Prefecture and the Kirgiz Autonomous Prefecture, a total area of very large, accounting for 67.16 percent of the total size of the Xinjiang region, Thus, a variety of tourism resources in the Xinjiang region are located in the southern border region. The vast area of the southern border region has a long history, with a variety of human resources and natural resources, as well as a variety of cultural sites, natural scenery is very unique, with a strong traditional culture. The southern border region, a total of five states, each state contains a very rich mineral resources, especially oil and gas resources are very rich Tarim Basin, in addition to resources, coal resources in other parts of the metal and non-metallic mineral deposit and other deposits in all very rich [1]. Furthermore, since the characteristics of the region of South Xinjiang, southern Xinjiang, the fruit is also very unique, Korla pear, apple heart Aksu sugar, etc. are well-known local crops, Loulan Old City, Bayinbuluke grassland and Bosten Lake, etc. at the local level very famous.

From our tourism resources survey for situation, the type of tourism resources in Xinjiang have very complete, six types have tourism resources. China's tourism resources, a total of 68 kinds of basic categories, and the type of tourism resources in Xinjiang region on up to 56 species, the proportion of very large. Six categories of species of Xinjiang Tourism Resources included are bio landscape tourism resources Landscape of Tourist Resources, monuments class tourism resources, shopping class tourism resources, ethnic customs class tourism resources and water landscape class tourism resources, species very complete. Natural tourism resources in the southern border region, 
many are fine, for example, the distribution of biological landscape Bayinbuluke Swan Lake, Altun Mountain Nature Reserve, also very extensive. Landscape of generally refers to the general mountain resort, canyons, sand, mountain expeditions, etc., the southern border of Landscape of including Nur Tuomuer, Ata peak, Tarim desert highway. Hydrological landscape generally include rivers, glaciers, Stephen King and reservoirs, lakes, southern hydrological landscape generally comprises Tarim, the Peacock, Karakoram Insukati Valley, Bachmann spa tower, size dragon pool, Golden Beach Wait. Climate biological landscape including astronomy meteorology, wildlife habitat and scenic grasslands, on behalf of the southern border region of biological landscape climate mainly desert mirage, Tianshan Tree Park and Tianshan Mysterious Grand Canyon [2].

In addition to the natural tourism resources, the southern region also has a very rich cultural tourism resources, ethnic customs and diverse history and culture of Xinjiang this region more attractive. Heritage southern region is very much more common Apak Hoja Tomb (Fragrant), Kizil Caves, Sam Sen wooden grotto, Hathpace houses, Miran and ancient sites such as Shule country. In addition, there are a lot of abstract humanistic attractions, including the opera and folk arts.

From the cultural and creative tourist sights of southern tourism resources for analysis, that is, the rich variety of tourism resources in the southern border region into cultural tourism resources, unique creativity driving force to build the southern border cultural tourism in South the development of tourism in Xinjiang into the more creative and innovative, so as to open up a new world. Although Xinjiang tourism resources are very rich, but if you do not innovate, then these tourism resources just to stay in the surface, the southern border of the tourism industry to develop, but the cultural and creative tourism has not done enough. From some of our other regions, although not so rich tourism resources and a wide variety, but from the sight of the cultural and creative tourism point of view, still achieved a great success.

For example, China Changzhou, although it is not a dinosaur area, but still Changzhou innovation, from the sight of the cultural and creative tourism, to create China's first dinosaur publicize and popularize knowledge Changzhou China Dinosaur Park, and has made great success, achieve the transformation of the development of tourism resources to develop tourism market, according to the actual market demand for the development of tourism, although do not have the natural advantage, but there are creative, or be able to further promote the development of tourism. For China Dinosaur Park, the reason why a great success, first of all because it captures the direction of the market, determine a theme creative by using a variety of high technology, high-grade cultural connotation into which the effective integration of tourism and science together to create a very distinctive theme, and the use of humane management methods, with the concept of the market to carry out tourism, effectively promote the common development of tourism and culture. In addition, Changzhou, Jiangsu Province, Nanjing in the interpretation of the group also created a derived from the arts and creative industries base, Chinese opera culture Exposition, also achieved very great success [3]. For, from South Xinjiang should sight the cultural and creative tourism point of view, to further promote tourism development in southern Xinjiang.

\section{Southern Xinjiang Tourism Development Strategy}

In recent years, the tourism development in southern Xinjiang, although the tourism resources in the southern border region is very rich, but not to integrate and transform a variety of cultural and creative tourism resources from a tourism perspective, leading to the use of tourism resources just stay in the very surface of the stage, many in the tourism value of the resources are being developed or have not yet developed status. Therefore, only from the sight of the cultural and creative tourism to the southern border of tourism resources and tourism integration in order to develop tourism in southern find a new way to shape a new image and attract more tourists. In southern tourism development process itself, should continue to learn from the successful experience of foreign and domestic cultural and creative tourism, a variety of tourism resources and the use of re-integration, excavated greater value. The primary task of the development of tourism in southern Xinjiang region is to update the concept, the development process in the past due to the impact of traditional values, the relatively slow development. At a time when the development of tourism in the southern 
border is at the bottleneck period, to get rid of bottlenecks during the development of tourism, the most important is to upgrade the concept that only innovative ideas in order to have a new development.

In recent years, the development of tourism in the southern border of either or on the basis of investment has been some development in the hardware investment, it shows the degree of attention on the country's southern border tourism development is increasing. However, the tourism industry in the development process, not only to do the work of the hardware, but also software to do the work, and take the road of innovation and development in order to solve problems currently encountered in the development of tourism in southern Xinjiang. From the current situation, the lack of development of southern tourism is from a cultural perspective and leading to the integration of a variety of tourism resources. Innovation and development of the concept of tourism is to take innovative and creative ideas to promote the development of tourism, the various tourism resources integration. A large number of facts have proven that innovation brings vitality, southern tourism only innovative ideas in order to enhance the image of the tourism industry, to break the bottleneck of tourism [4].

Tourism industry is a very good development prospects of industry, but in recent years the competitiveness of the tourism industry is very large, in order to succeed in the highly competitive market, it is necessary to create a good image, by shaping a good image of the southern the development of tourism has become a huge target of western tourism resort. In order to effectively enhance the image of tourism in southern Xinjiang, southern markets will sell first to do the work of tourism development. Whether it is for a country or for a region, the image has a very important position, especially for the tourism industry. In the process of development of tourism, the strategy is reflected in the image of soft power in the region, only creates a good image, in order to make the entire region more attractive, thereby enhancing the market appeal. In southern tourism in the past is a very good image in front of people, and therefore formed a good reputation. But in recent years, due to some other factors in Xinjiang for tourism development in southern Xinjiang has had some impact, southern tourism and the retail trade are subject to certain impact. These factors initially caused some southern travel league phenomenon, so that tourists when travel is also a certain amount of psychological burden to bear, a number of other sectors have also been affected, resulting in the image of tourism in Xinjiang also received a corresponding impact [5]. For this, the southern border tourism should think how to respond to reshape a charm, harmony, security image and attract more tourists.

For this, the southern border tourism can be promoted through various channels, advertising, television, Internet and so on. For tourism image not only from the form of a single embodiment, but rather clever use of various combinations of ways to solve the side, mainly to showcase the charm of southern mainly to re-create a good image. In the process of re-shaping the image should be clever use of various promotional techniques, various outstanding creative for the southern periphery tourism industry brands should seriously study the successful experience at home and abroad. Simply to attract visitors through the eyes of visual landscaping is not enough, at the same time vigorously promote the natural landscape, it should promote its cultural connotations, creating a rich cultural heritage.

Modern tourism have become increasingly demanding, simple visual experience can not meet people's needs, therefore, southern tourism in the development process, in order to seek better development, the tourism industry and can also be integrated in the cultural industries performed together development, to show the beautiful nature, but also the southern border of cultural heritage should be shown to meet the spiritual needs of people, not only increases the content of cultural industries, but also effectively extend the tourism industry chain, so the added value of the tourism industry greatly increased. Creative thinking is the use of tourism itself creative industries to integrate and use of tourism resources and innovative new tourism products, development of the tourism industry chain extension. And compared to traditional development of tourism industry, tourism is the cultural and creative depth integration in the development process of tourism, the tourism industry entered the cultural soul of every tourism activity can be carried out by way of 
culture, in the tourism economic activities in many areas can contains local cultural and creative factors, production and consumption of tourism products is built on the foundation of cultural creativity on [6]. Tourism and creative industries emphasize that a new concept, breaking the single perspective of the tourism industry, the realization of various tourism resources in South multidimensional integration.

\section{Conclusion}

From a cultural perspective on the integration of tourism resources, can achieve nothing, one can be fight against ten and have excellent high school students, through tourism and cultural innovation, can effectively gather more talent. Cultural and creative perspective to the development of tourism, not just a great progress in the concept, but also be able to gather more creative talents, so that the southern border tourism development has a new driving force, to achieve the diverse southern tourism resources multidimensional integration.

\section{Acknowledgement}

Project: New Century Talents Support Program (NCET-13-0925);

The Xinjiang Production and Construction Corps excellence project;

Tarim University principal Fund Project.

\section{References}

[1] Wang Huijun. Xinjiang Tourism Development in the cultural and creative tourism Perspective [J]. Xinjiang Social Science, 2011, 29 (06): 106-111.

[2] Yang Jieming, Xu Hui. Ethnic Areas in South Xinjiang Tourism Development and Discipline Construction [J]. Chinese suppliers theory, 2016, 32 (14): 36-37.

[3] Tuerxuntuoheti Maitusong, Ayiguli Kelimula. Southern Xinjiang area of tourism development and tourism personnel training [J]. Entrepreneur Economic Yearbook•Educational Research Universities., 2013, 28 (5): 154-155.

[4] Yu Yanqiu, Yan Yan. Northwest Ethnic Area Tourism Development of the agricultural heritage protection Perspective - In Southern Xinjiang oasis agriculture system as an example [J]. Jiangxi Agricultural Sciences, 2010, 22 (07): 210 -211.

[5] Wang Shuyun, Yu Xiaoling, Liu Bin. Affect the five southern states of Xinjiang Tourism Industry Analysis and Countermeasures [J]. Market Modernization, 2009, 35 (12): 228-229.

[6] Re Na. advance research by leaps and bounds five southern states tourism [J]. Zhejiang Tourism Vocational College, 2013, 14 (1): 65-66. 